\title{
Naltrexone does not disrupt acquisition or performance of inhibitory conditioning
}

\author{
JESUS LANDEIRA-FERNANDEZ, MICHAEL S. FANSELOW, JOSEPH P. DECOLA, \\ and JEANSOK J. KIM \\ University of California, Los Angeles, California
}

\begin{abstract}
Previous research has demonstrated that naltrexone (NTX) enhances acquisition of aversive excitatory Pavlovian conditioning. Both the conditional opponent theory (Schull, 1979) and the perceived intensity hypothesis (Fanselow, 1981; Young \& Fanselow, 1992) accurately predict this result. Nevertheless, these two models make different predictions about the effects of NTX on inhibitory conditioning. In the present experiment, these predictions were tested by investigating the effect of NTX on the acquisition and expression of inhibitory conditioning. NTX was injected during conditioned inhibitory (CI) training or testing. To avoid an effect of NTX on excitatory conditioning, excitatory and inhibitory trials were separated by $24 \mathrm{~h}$. A control group was used to assess acquisition of CI. It was found that NTX did not disrupt acquisition or expression of CI. These results are inconsistent with the conditional opponent theory but are in accordance with the perceived intensity hypothesis.
\end{abstract}

Treatment with opioid antagonists during training involving aversive stimulation, such as footshock, causes an increase in acquisition of fear conditioning (Ehrman, Josephson, Schull, \& Sparich, 1979; Fanselow \& Bolles, 1979; Gallagher \& Kapp, 1978). Two models of aversive Pavlovian conditioning - the conditioned opponent theory developed by Schull (1979) and the perceived intensity hypothesis developed by Fanselow $(1981,1984 a$; Young \& Fanselow, 1992)-offer distinct accounts of this result.

The conditioned opponent process theory proposes that an aversive stimulus produces its primary hedonic reaction, a-process, followed by an opposite hedonic response, b-process. This b-process functions to reduce the primary hedonic reactions produced by the aversive stimulus. This process is assumed to be mainly a conditional response that grows with consecutive presentations of the aversive stimulus. The animal's affective state in response to the aversive stimulus is a summation of these two opposite processes. When the a-process is bigger than the $b$ process, an A-state results; when the b-process is bigger than the a-process, a B-state results. The A-state is responsible for Pavlovian fear conditioning and has its maximum efficacy when the aversive stimulus is presented for the first time. With successive aversive stimulation, the bprocess increases, causing a reduction in the A-state. The conditioned opponent theory suggests that endogenous

This research was supported by National Institute of Mental Health Grant MH39786 to M. S. F. J. Landeira-Fernandez was supported by a fellowship from Conselho Nacional de Desenvolvimento Científico of the Ministry of Science, Brazil. The authors thank Kathy Chin for editorial assistance. J. J. Kim is now at the University of Southern California. Correspondence should be addressed to M. S. Fanselow, Department of Psychology, University of California, Los Angeles, CA 90024-1563. opioids are the physiological substrate of the b-process (Schull, 1979). This model ascribes the facilitatory effect of opioid antagonists on fear conditioning to a blockade of the b-process and a concomitant increase in the A-state. This enhancement of the affective reaction to the aversive stimulus (A-state), produced by the blockade of the compensatory hedonic response to the same aversive stimulus (b-process), produces the facilitatory effects of opioid antagonists in aversive conditioning.

Alternatively, the perceived intensity hypothesis proposes that the facilitatory effect of opioid antagonists on aversive Pavlovian conditioning causes the disruption of the opioid conditional analgesia that is elicited by stimuli associated with the aversive stimulus. It has been demonstrated that there is a reduction in pain sensitivity/ reactivity when an animal is exposed to a stimulus previously paired with shock (Chance, White, Krynock, \& Rosecrans, 1977; Fanselow, 1984b; Fanselow \& Bolles, 1979; Hayes, Bennett, Newlon, \& Mayer, 1978; Helmstetter \& Fanselow, 1987; MacLennan, Jackson, \& Maier, 1980; Ross \& Randich, 1985; Watkins, Cobelli, \& Mayer, 1982). Moreover, it has been shown that the analgesia triggered by conditional stimuli is often mediated by endogenous opioids (Calcagnetti, Helmstetter, \& Fanselow, 1987; Fanselow, 1984b; Fanselow \& Bolles, 1979; Helmstetter \& Landeira-Fernandez, 1990; Watkins, Cobelli \& Mayer, 1982). In this way, the perceived intensity hypothesis proposes a mechanism in which the opioid analgesia that develops during aversive conditioning reduces the physical impact of the aversive stimulus. Opioid antagonists block this conditional analgesic response, which results in an increase in the sensation and/or perception of the aversive stimulus. This increase in pain results in the facilitatory effects of opioid antagonists on aversive conditioning. 
Although both models accurately predict the enhancement of the acquisition of Pavlovian fear conditioning produced by opioid antagonists, they make different predictions concerning inhibitory conditioning of fear. In aversive conditioning, a conditioned inhibitory stimulus reduces conditional fear. According to the conditioned opponent theory, conditioned inhibition (CI) is acquired when a neutral stimulus is paired with the b-process. Since this theory states that endogenous opioids mediate this compensatory response, it predicts that opioid antagonists should prevent or attenuate the development of CI. Moreover, the conditioned opponent process theory suggests that the expression of CI depends on the activation of the b-process, predicting that opioid antagonists should also block the expression of CI. In contrast to these predictions, the perceived intensity hypothesis suggests that opioid antagonists influence conditioning only through their antagonism of conditional analgesia. During inhibitory conditioning, no aversive stimulation is presented; therefore, the perceived intensity hypotheses proposes that opioid antagonists should not attenuate the acquisition or expression of $\mathrm{CI}$.

The influence of opioid antagonist on the expression of CI was studied by Blazis and Moore (1982). In their experiment, rabbits were employed as subjects and the nictitating membrane response served as the index of conditioning. Animals were trained with a conditioned inhibitory procedure and, after they had acquired the response, they were treated with the opioid antagonist naloxone or saline. It was found that naloxone had no effect on the expression of CI. However, the effect of opioid antagonists on the expression of CI has yet to be examined directly in fear conditioning, which is where the facilitatory effects of opioid antagonists have most frequently been studied. Additionally, there is no information on the effect of opioid antagonists on the acquisition of CI. In the present experiment, the impact of naltrexone (NTX), an opioid antagonist, on the acquisition and expression of $\mathrm{CI}$ in rats was studied. Freezing, an innate response to fear, was employed to assess aversive conditioning.

\section{METHOD}

\section{Subjects}

Fifty female Long-Evans rats, between 70 and 90 days old and weighing $220-300 \mathrm{~g}$, served as subjects. They were born and raised in the UCLA Psychology Department colony. The animals were individually housed in hanging stainless steel cages with ad-lib food and water. All rats were experimentally naive, and each animal was briefly handled for 5 days before the start of the experiment. The experiment was conducted during the light portion of a 12:12-h light:dark cycle.

\footnotetext{
Apparatus

Four identical chambers measuring $28 \times 21 \times 10.5 \mathrm{~cm}$ (Lafayette Instrument Co.), placed inside sound- and light-attenuating chests, were used for conditioning and observation. Each chamber contained a white houselight (1820 bayonet bulb, $28 \mathrm{~V}$ ) located on a side wall. Opposite to that wall was a speaker through which a white noise ( $82 \mathrm{~dB}$ A scale) or a pure tone $(3000 \mathrm{~Hz}, 84 \mathrm{~dB}$ A scale) could be presented. Ventilation fans supplied background noise (68 dB A scale). The floor of each chamber was composed of 18 stainless steel rods (4 mm diameter), spaced $1.5 \mathrm{~cm}$ center to center. Individual shock generators and scram-
}

blers (Lafayette Instrument Co.) were wired to each chamber and were adjusted to deliver a 1-mA shock. An ammonium hydroxide solution (5\% was used to clean the chambers prior to and after each subject.

All chambers could be altered in order to provide a different stimulus environment (test context). A piece of wood was diagonally placed across each chamber, such that the wall containing the houselight remained uncovered. Moreover, the ventilation fans were turned off, and tap water instead of ammonium hydroxide was used to clean the chambers. Finally, $1.0 \mathrm{ml}$ of imitation almond extract was placed under the grid floor of each test chamber.

\section{Procedure}

The 50 animals were randomly assigned to five groups containing 10 subjects each. Four of these groups were trained in a procedure that consisted of eight excitatory and eight inhibitory sessions. Each session, spaced $24 \mathrm{~h}$ apart, consisted of three trials. In the excitatory sessions, the tone was presented for $60 \mathrm{sec}$, and a 1-sec, 1-mA electric shock was presented during the last second of the tone $(\mathrm{A}+)$. In the inhibitory sessions, the tone and light were presented together for $60 \mathrm{sec}$, and no shock was presented $(\mathrm{AB}-)$. The interval between trials in both session types was variable, ranging from 140 to $420 \mathrm{sec}$. Session type (excitatory or inhibitory) was determined randomly, with the constraints that the first session was excitatory and a maximum of three sessions of the same type could occur consecutively. Two groups were injected with NTX $(7 \mathrm{mg} / \mathrm{kg}$, i.p.) $10 \mathrm{~min}$ before the beginning of an inhibitory session and saline prior to the beginning of an excitatory session. This NTX dose was chosen because of its ability to reverse conditional analgesia and enhance aversive conditioning (Fanselow \& Baackes, 1982; Helmstetter \& Fanselow, 1987). The two other groups received saline before both types of sessions. A fifth group, which served as a control group for inhibitory conditioning, received the same procedure as the others with the exception that during the excitatory sessions a white noise $(\mathrm{C}+)$, instead of a tone, was employed. The $\mathrm{C}+$ group had saline injected during both excitatory and inhibitory sessions.

On Day 17, all animals were exposed to a novel test context for $3 \mathrm{~min}$. After this period, five unsignaled electric shocks, $60 \mathrm{sec}$ apart, were delivered. No drug or saline was injected during this phase. This treatment was instituted to establish an excitatory baseline against which to assess CI. On Day 18, the animals were reexposed to the test context and, $3 \mathrm{~min}$ later, the light was presented for $10 \mathrm{~min}$. The two groups treated with NTX during the inhibitory sessions were injected with NTX (NTX/NTX) or saline (NTX/SAL). The two other groups treated with saline during the inhibitory sessions received NTX (SAL/NTX) or saline (SAL/SAL). In order to measure pain sensitivity during testing, all animals were injected with $0.05 \mathrm{ml}$ of a $15 \%$ formalin solution subcutaneously into the dorsal area of the right hind paw $30 \mathrm{~min}$ before the beginning of the test. During this test day, freezing (defined as the absence of any visible movement of the body and vibrissa except for movement necessary for respiration), and formalin-induced behaviors (defined by paw lifting or paw licking; see Fanselow, 1984b) were scored with a time sample procedure. An experimenter unaware of the experimental conditions recorded formalin-induced behavior, general activity, or freezing. Freezing and formalin induced behavior were scored hierarchically. If an animal was freezing and presenting the formalin behavior at the same time, only the formalin behavior was considered. ${ }^{1}$

\section{RESULTS}

Figure 1 presents the percent of samples scored as freezing for the five groups in the test context prior to the presentation of the conditioned inhibitor. A one-way analysis of variance (ANOVA) revealed no differences among the groups $[F(4,45)=1.387, p>.25]$. This result suggests that all groups had the same level of baseline fear in the test context. Since animals typically do not freeze more than $5 \%$ to a novel context (Fanselow, 1984b), the high levels of freezing observed during the baseline was conditioned by the five shocks. 


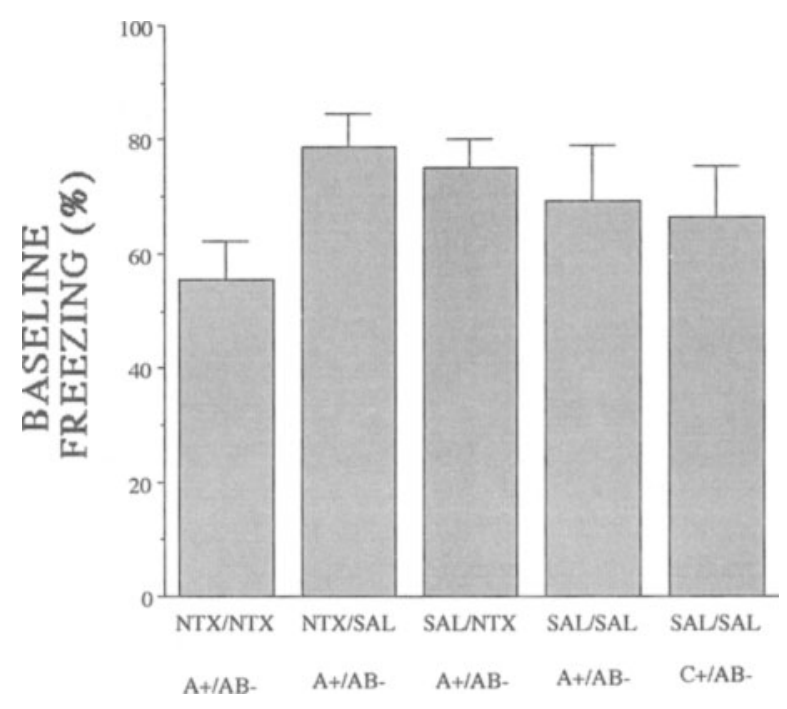

Figure 1. Mean percentage freezing in the test context prior to the presentation of the conditioned inhibitor.

On the basis of this result, the measure of inhibitory conditioning was taken to be the difference between the mean percentage of freezing during the 3-min baseline and the mean percentage of freezing during the $10 \mathrm{~min}$ during which the light was presented. These results are presented in Figure 2. A one-way ANOVA revealed a reliable difference among groups $[F(4,45)=3.02, p<$ $.03]$. The presence of inhibitory conditioning is indicated by the reliable difference between the inhibitory control group that received a white noise instead of tone during excitatory conditioning $(\mathrm{C}+/ \mathrm{AB}-)$ and the sum of the four conditioned inhibitor groups that received the same

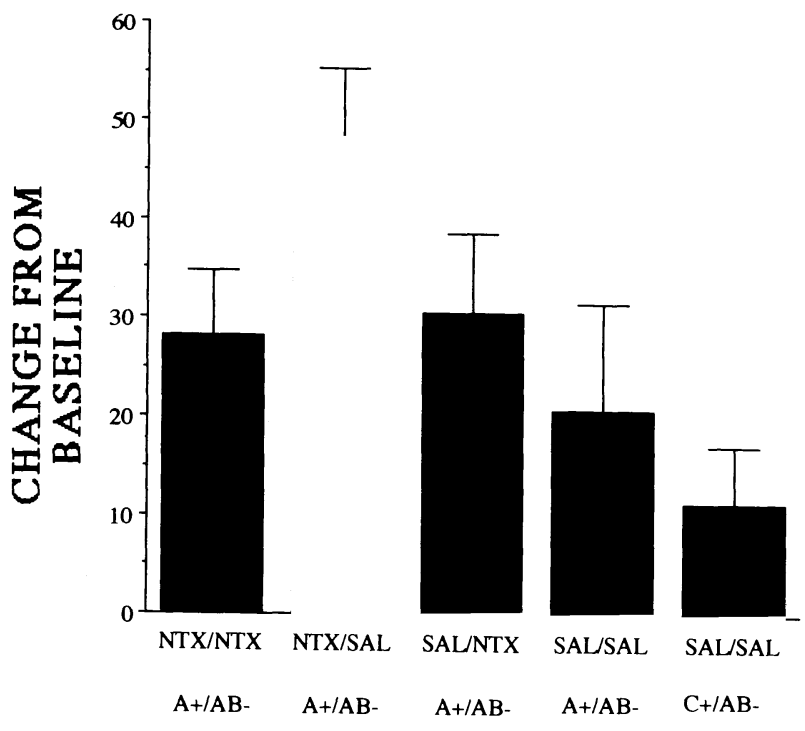

Figure 2. Difference in mean percentage freezing between baseline and presentation of the conditioned inhibitor. Larger difference score indicates greater inhibition. behavioral procedure $(\mathrm{A}+/ \mathrm{AB}-)[F(1,45)=5.54, p<$ $.03]$. As will be discussed below, these four groups did not differ.

\section{DISCUSSION}

NTX did not affect expression or performance of CI since the group trained under saline and tested under NTX (SAL/NTX) exhibited the same amount of inhibitory conditioning as did the group trained and tested under saline (SAL/SAL). This result is in agreement with Blazis and Moore's (1982) study and suggests that endogenous opioids are not involved in the inhibition of fear. This outcome does not support the prediction of the conditioned opponent theory that the expression of $\mathrm{CI}$ depends on the release of endogenous opioids and that NTX disrupts the expression of $\mathrm{CI}$.

NTX also did not attenuate acquisition of $\mathrm{CI}$. The groups treated with NTX during training and tested under saline (NTX/SAL) and NTX (NTX/NTX) did not differ reliably from the group that was injected with saline on both training and test (SAL/SAL). In fact, the Group NTX/SAL, trained under NTX, tended to show more inhibitory conditioning than did Group SAL/SAL, which received the CI training under saline, although the trend fell short of statistical significance. These results did not support the conditioned opponent theory's prediction that NTX prevents acquisition of CI. As described in the introduction, the conditioned opponent theory states that inhibitory conditioning is acquired by pairing a neutral stimulus with the endogenous opioid mediated b-process.

As a whole, the present results demonstrated that NTX did not attenuate acquisition or performance of CI. Furthermore, the results failed to provide support for the conditioned opponent theory based on a compensatory hedonic response mediated by endogenous opioids. Although these results cannot rule out the existence of this compensatory response postulated by the conditioned opponent theory, they suggest that endogenous opioids are not involved in it. Therefore, the theory's explanation for the facilitatory effect of NTX on fear conditioning, via an opioid compensatory response, should be reconsidered. However, these results provided support for the perceived intensity hypothesis, which predicts that NTX should not affect learning or performance of conditional fear-related behavior when given in the absence of primary painful stimuli.

\section{REFERENCES}

Blazis, D. J., \& Moore, J. W. (1982). Naloxone does not impair conditioned inhibition of the rabbit's nictitating membrane response. Bulletin of the Psychonomic Society, 22, 122-123.

Calcagnetti, D. J., Helmstetter, F. J., \& Fanselow, M. S. (1987). Quaternary naltrexone reveals the central mediation of conditional opioid analgesia. Pharmacology, Biochemistry \& Behavior, 27, 529-531.

Chance, W. T., White, A. C., KrYNock, G. M., \& Rosecrans, J. A. (1977). Autoanalgesia: behaviorally activated antinoception. European Journal of Pharmacology, 44, 283-284.

Ehrman, R. N., Josephson, P. J., SChull, J., \& Sparich, C. (1979, April). Behavioral effects of the endorphin systems within instrumental \& classical conditioning paradigms. Paper presented at the 50th meeting of the Eastern Psychological Association, Philadelphia.

FANSELOW, M. S. (1981). Naloxone and Pavlovian fear conditioning. Learning \& Motivation, 12, 398-419.

FANSELOW, M. S. (1984a). Opiate modulation of the active and inactive components of the postshock reaction: Parallels between naloxone pretreatment and shock intensity. Behavioral Neuroscience, 98, 269-277.

FANSELOW, M. S. (1984b). Shock-induced analgesia on the formalin test: effects of shock severity, naloxone, hypophysectomy, and associative variables. Behavioral Neuroscience, 98, 79-95.

FANSElow, M. S., \& BAACKES, M. P. (1982). Conditioned fear-induced opiate analgesia on the Formalin test: Evidence for two aversive motivational systems. Learning \& Motivation, 13, 200-221. 
Fanselow M. S., \& Bolles, R. C. (1979). Triggering of the endorphinergic analgesia reaction by a cue previously associated with shock: reversal by naloxone. Bulletin of the Psychonomic Society, 14, 88-90.

GALlAGHER, M., \& KAPP, B. S. (1978). Manipulation of opiate activity in the amygdala alters memory processes. Life Science, 23, 1973-1978.

Hayes, R. L., Bennett, G. J., Newlon, P. G., \& Mayer, D. J. (1978). Behavioral and physiological studies of non-narcotic analgesia in the rat elicit by certain environmental stimuli. Brain Research, 166, 69-90.

Helmstetter, F. J., \& Fanselow, M. S. (1987). Effects of naltrexone on learning and performance of conditional fear-induced freezing and opioid analgesia. Physiology \& Behavior, 39, 501-505.

Helmstetter, F. J., \& LANDEIRA-Fernandez, J. (1990). Conditional hypoalgesia is attenuated by naltrexone applied to the periaquedutal gray. Brain Research, 537, 88-92.

MacLennan, A. J., Jackson, R. L., \& Maier, S. F. (1980). Conditioned analgesia in the rat. Bulletin of the Psychonomic Society, 15, 387-390.

Ross, R. T., \& RANDICH, A. (1985). Associative aspects of conditioned analgesia evoked by a discrete CS. Animal Learning \& Behavior, 13, 419-431.
SCHUll, J. (1979). A conditioned opponent theory of Pavlovian conditioning and habituation. Psychology of Learning \& Motivation, 44, 57-90.

Watkins, L. R., Cobelli, D. A., \& Mayer, D. J. (1982). Classical conditioning of front and hind paw foot shock induced analgesia (FSIA). Naloxone reversibility and descending pathways. Brain $\mathbf{R e}$ search, 243, 119-132.

Young, S. L., \& FANSElow, M. S. (1992). Associative regulation of Pavlovian fear conditioning: unconditional stimulus intensity, incentive shifts, and latent inhibition. Journal of Experimental Psychology: Animal Behavior Process, 18, 400-413.

\section{NOTES}

1. Formalin-induced behaviors rarely occurred during the testing session; therefore only freezing was analyzed.

(Manuscript received July 1, 1993.) 